\title{
Porcelanas elétricas aluminosas: Parte II - desenvolvimento da microestrutura e sua influência no módulo de ruptura
}

\section{(Aluminous electrical porcelains: Part II - microstructural development and its influence on the bending strength)}

\author{
A. L. Chinelatto ${ }^{1}$, D. P. F. de Souza ${ }^{2}$ \\ ${ }^{1}$ Departamento de Engenharia de Materiais, Universidade Estadual de Ponta Grossa \\ Av. Carlos Cavalcanti 4748, Ponta Grossa, PR 84030-900 \\ ${ }^{2}$ Departamento de Engenharia de Materiais, Universidade Federal de S. Carlos \\ Rod. Washington Luiz, km 235, C. P. 676, S. Carlos, SP 13565-905 \\ adilson@uepg.br,dulcina@power.ufscar.br
}

\begin{abstract}
Resumo
A microestrutura e o módulo de ruptura de porcelanas aluminosas foram analisados com o aumento da temperatura de sinterização. Foi determinado que quando o teor de alumina é elevado o processo de rearranjo das partículas durante a sinterização é inibido devido à formação do esqueleto de partículas de alumina as quais são insolúveis na fase líquida. O módulo de ruptura aumenta com a quantidade de fase cristalina sendo que as partículas de alumina contribuem de forma mais efetiva para este aumento do que os cristais de mulita. Palavras-chave: porcelana elétrica aluminosa, microestrutura, módulo de ruptura.
\end{abstract}

\begin{abstract}
The microstructure and bending strength of aluminous porcelains were analyzed at rising sintering temperatures. It was found that, in the presence of high alumina content, the particle rearrangement process during sintering is inhibited by the formation of a skeleton of alumina particles that are insoluble in the liquid phase. The bending strength increases along with the amount of crystalline phase, with the alumina particles contributing more effectively to this increase than the mullite crystals.

Keywords: aluminous electrical porcelain, microstructure, bending strength.
\end{abstract}

\section{INTRODUÇÃO}

Porcelanas são produzidas a partir da mistura de matériasprimas naturais que, por sua vez contém vários componentes e, geralmente, com larga distribuição granulométrica. Por conseqüência, a microestrutura das porcelanas é multifásica e cada fase com suas peculiaridades tais como: amorfa ou cristalina, tamanho e forma de grão, coeficiente de expansão, transição de fase. Além das diferentes fases a microestrutura das porcelanas contém defeitos introduzidos devido às características intrínsecas das matérias-primas ou interações entre elas em alta temperatura ou devido ao processamento cerâmico.

As propriedades dos materiais cerâmicos são essencialmente dependentes da microestrutura. No caso das porcelanas a propriedade mais sensível à microestrutura é a propriedade mecânica. Como já mencionado na parte I [1], a busca pela melhoria desta propriedade levou à substituição do quartzo por alumina nas composições das porcelanas pois desta forma elimina-se um grande número de defeitos introduzidos pela transição de fase que as partículas de quartzo sofrem no resfriamento. Contudo, nas porcelanas triaxiais aluminosas uma infinidade de composições são possíveis e cada uma delas com sua microestrutura e propriedades características. Porém, um entendimento geral do desenvolvimento das microestruturas dentro deste sistema auxilia na formulação de composições específicas.

Neste trabalho são apresentados resultados sobre o módulo de ruptura e a evolução da microestrutura com a temperatura de sinterização de três composições de porcelanas aluminosas preparadas com matérias primas naturais nacionais.

\section{PROCEDIMENTO EXPERIMENTAL}

Matérias-primas: As porcelanas foram preparadas utilizando as seguintes matérias-primas: alumina alfa; feldspato potássico; caulim e argila plástica. Para cada matéria prima natural foi obtido: composição mineralógica, porcentagem em peso da fração +325 mesh, distribuição granulométrica da fração -325 mesh. A alumina foi submetida à difração de raios $\mathrm{X}$ e medida da distribuição granulométrica.

Composições estudadas

A escolha das composições levou em consideração apenas 
o interesse em comparar o desenvolvimento da microestrutura e módulo de ruptura entre uma composição rica em caulim (composição F), em alumina (composição G) e em feldspato (composição H). Em todas as composições foi adicionado 10\% em peso de argila plástica para auxiliar no processo de conformação. A Tabela I mostra as composições utilizadas e na Fig. 1 cada composição é situada no diagrama caulimalumina-feldspato sem levar em consideração a argila plástica.

Tabela I - Denominação das composições. [Table I - Compositions denomination.]

\begin{tabular}{lccc}
\hline Matéria-prima & \multicolumn{3}{c}{$\begin{array}{c}\text { Composições } \\
(\% \text { em peso })\end{array}$} \\
& $\mathrm{F}$ & $\mathrm{G}$ & $\mathrm{H}$ \\
\hline Alumina & 18 & 54 & 18 \\
\hline Feldspato & 18 & 18 & 54 \\
\hline Caulim & 54 & 18 & 18 \\
\hline Argila & 10 & 10 & 10 \\
\hline
\end{tabular}

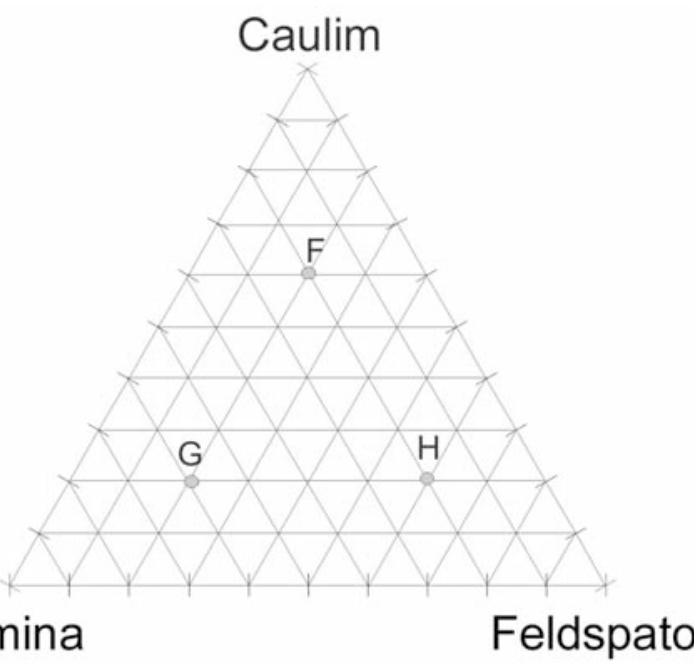

Figura 1: Localização das composições F, G e H no diagrama triaxial alumina-caulim-feldspato (cada divisão do diagrama equivale a $10 \%$ em peso).

[Figure 1: Location of the compositions $F, G$ e $H$ on the aluminakaolin-feldspar phase diagram.]

\section{Preparação dos corpos de prova}

Foi utilizado o procedimento usual de mistura a úmido das matérias primas em moinho de bolas com a adição de silicato de sódio como defloculante. As suspensões foram secas em estufas até atingir umidade de $\sim 5 \%$ e em seguida o pó foi desaglomerado em malha 50 mesh. Os corpos de prova, na forma de pastilhas e barrinhas, foram prensados uniaxialmente e sinterizados, ao ar em forno elétrico, entre $1200^{\circ} \mathrm{C}$ e $1450{ }^{\circ} \mathrm{C}$, com incremento de $50^{\circ} \mathrm{C}$ entre as temperaturas de sinterização. O patamar de queima na temperatura de sinterização foi de 1 hora. A taxa de aquecimento utilizada foi $300{ }^{\circ} \mathrm{C} / \mathrm{h}$ até $1000^{\circ} \mathrm{C}$ e $200^{\circ} \mathrm{C} / \mathrm{h}$ até atingir a temperatura de sinterização.

\section{Caracterização dos corpos de prova}

Os corpos de prova verdes foram submetidos a ensaios de dilatometria (Netzsch modelo 402C). Os corpos de prova sinterizados foram analisados pelas seguintes técnicas: microscopia eletrônica de varredura, MEV (Philips XL-30 FEG) associada com microanálise por energia dispersiva (EDS) em amostras polidas e atacadas com solução de $5 \%$ HF por 45 segundos; difração de raios X (Siemens D5000) tanto para identificação de fases como para medida do tamanho dos cristalitos de mulita pelo método Scherrer; medida da constante dielétrica com eletrodos de prata (HP 4192A); medida da densidade pela técnica de imersão e medida do módulo de ruptura por flexão em três pontos (máquina Instron). Detalhes de todos os procedimentos podem ser obtidos em [2].

\section{RESULTADOS E DISCUSSÃO}

Matérias-primas: Em se tratando de porcelanas aluminosas, o teor de quartzo presente nas matérias primas naturais é um parâmetro importante. A Tabela II mostra a porcentagem de argilominerais e minerais majoritários presentes em cada matéria prima sendo a argila a que apresenta maior teor de quartzo. A Fig. 2 mostra a distribuição granulométrica da alumina e da fração -325 mesh das matérias primas naturais. A determinação da fração +325 mesh de cada matéria-prima natural forneceu: $10,6 \%$ na argila, $3,9 \%$ no caulim e $12,4 \%$ no feldspato, porcentagem em peso.

Tabela II - Minerais e argilominerais majoritários presentes nas matérias-primas naturais (\% em peso)

[Table II - Majority minerals and clay minerals present on the raw materials (weight \%).]

\begin{tabular}{lll}
\hline Caulim & Mica & 6,3 \\
\cline { 2 - 3 } & Caulinita & 90,4 \\
\cline { 2 - 3 } & Quartzo & 1,1 \\
\hline Argila & Mica & 3,0 \\
\cline { 2 - 3 } & Caulinita & 87,4 \\
\cline { 2 - 3 } & Quartzo & 7,4 \\
\hline Feldspato & Microclínio & 63,8 \\
\cline { 2 - 3 } & Albita & 25,2 \\
\cline { 2 - 3 } & Quartzo & 6,6 \\
\hline
\end{tabular}

Corpos sinterizados: Os resultados obtidos para cada composição serão apresentados separadamente visto que a ênfase é apresentar a evolução da microestrutura e do módulo 


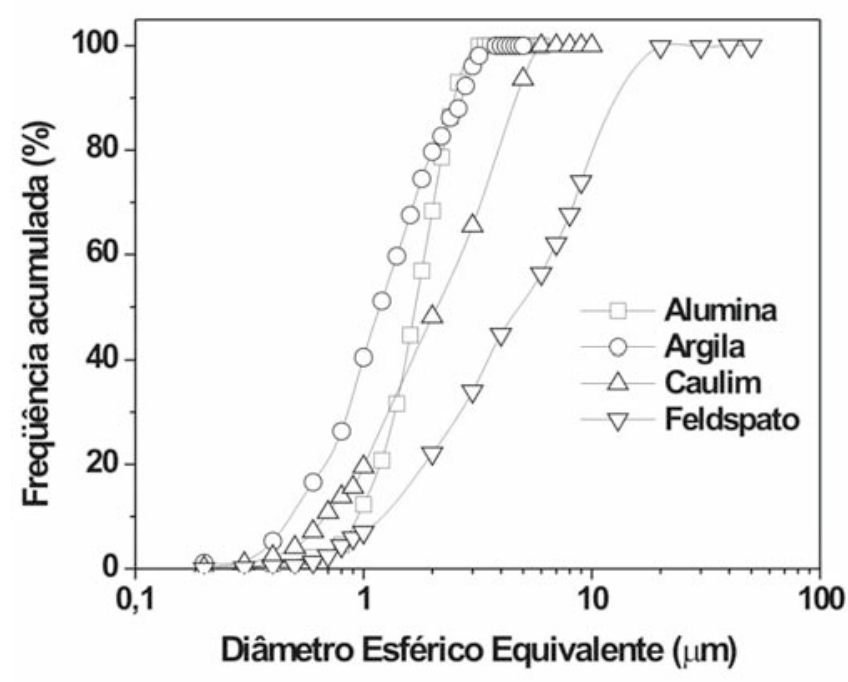

Figura 2: Distribuição granulométrica das matérias primas (fração -325 mesh).

[Figure 2: Particle size distribution of the raw materials (-325 mesh portion).]

de ruptura com a temperatura de sinterização para cada composição. No final é feita uma comparação entre as três composições.

Composição F (54\% de feldspato, 18\% de caulime 18\% alumina) A dependência da densidade com a temperatura de

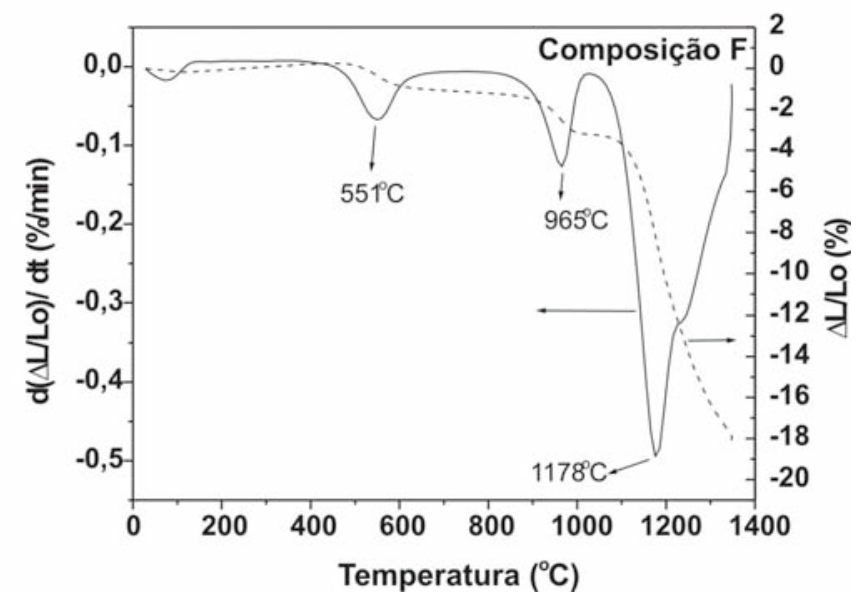

Figura 4: Curva de dilatometria e sua derivada primeira da composição F. Taxa de aquecimento: $5^{\circ} \mathrm{C} / \mathrm{min}$.

[Figure 4: Dilatometric curves and the shrinkage rate as a function of the temperature of composition F. Heating rate: $5{ }^{\circ} \mathrm{C} / \mathrm{min}$.]

sinterização da composição $\mathrm{F}$ é apresentada na Fig. 3. O incremento na densidade entre $1100^{\circ} \mathrm{C}$ e $1150^{\circ} \mathrm{C}$ é atribuído ao rearranjo das partículas em conseqüência do aparecimento da fase líquida. Entre $1150{ }^{\circ} \mathrm{C}$ e $1200{ }^{\circ} \mathrm{C}$ ocorre redução na taxa de densificação indicando o final do processo de rearranjo das partículas. Um outro aumento significativo na densidade é observado entre a $1200{ }^{\circ} \mathrm{C}$ e $1250{ }^{\circ} \mathrm{C}$ atribuído ao processo de dissolução-reprecipitação, que passa a ser dominante. Entre $1250^{\circ} \mathrm{C}$

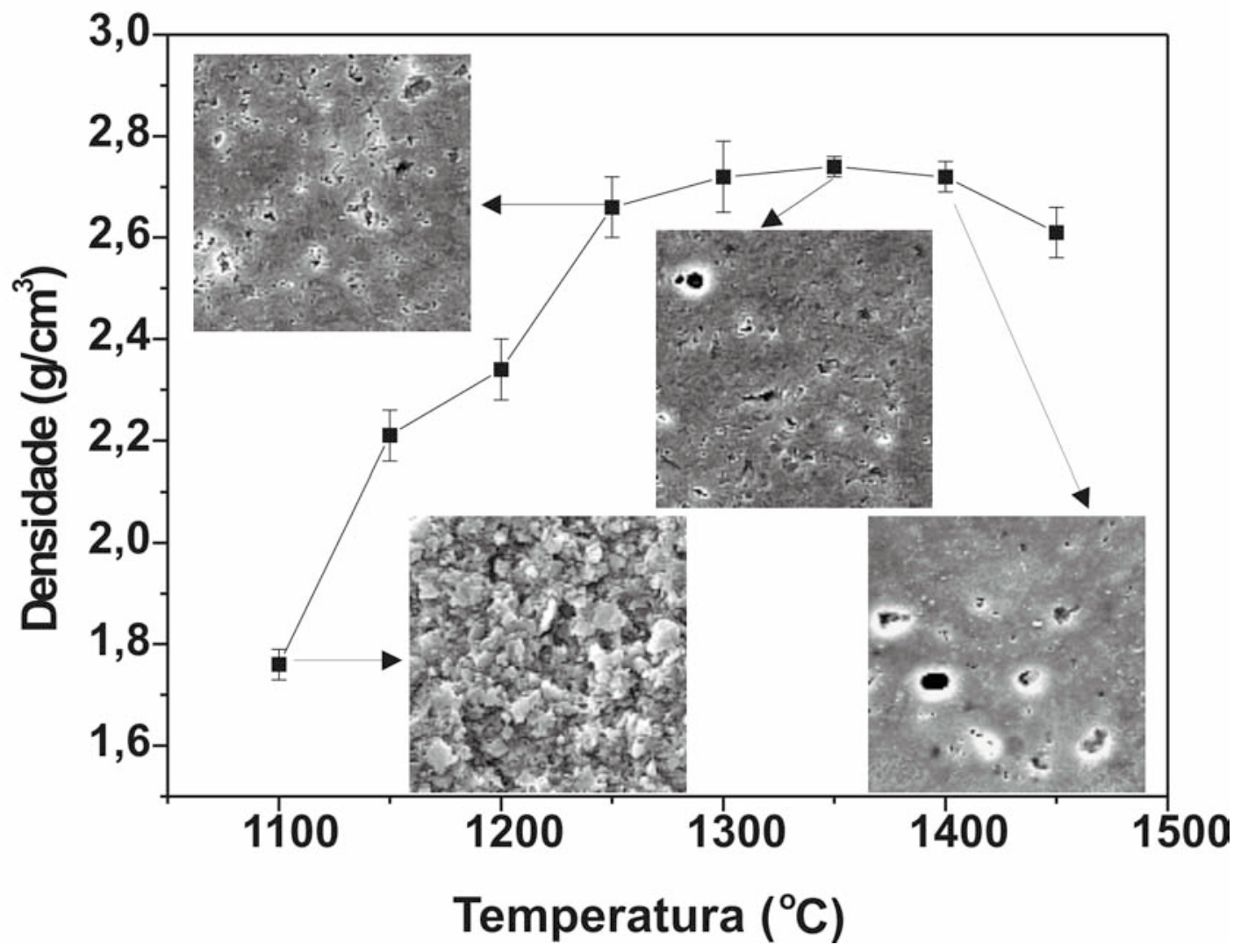

Figura 3: Densidade de amostras sinterizadas e microestruturas características da composição F em função da temperatura de sinterização. [Figure 3: Density of sintered samples and characteristic microstructures of composition F as a function of sintering temperature.] 


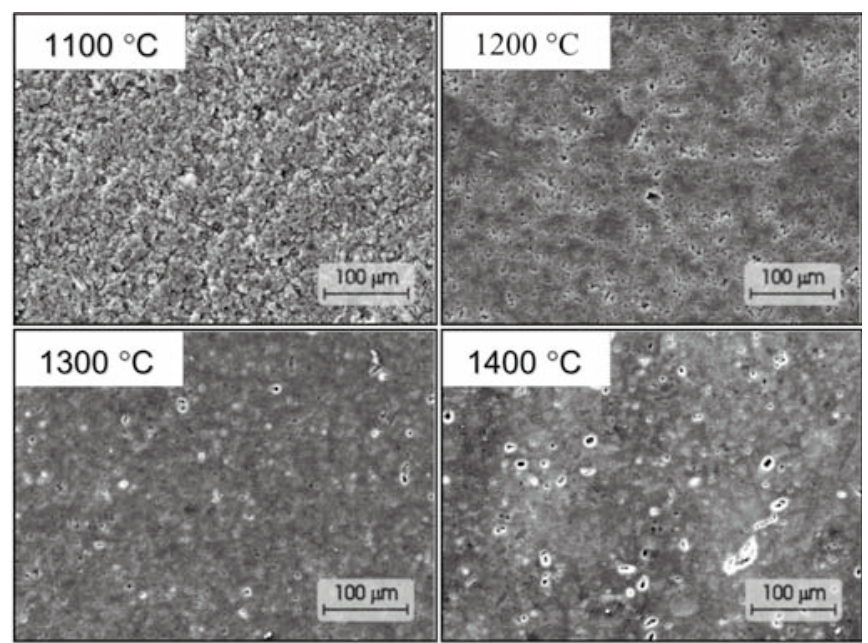

Figura 5: Micrografias obtidas por $\mathrm{MEV}$ da composição $\mathrm{F}$ sinterizada a $1100{ }^{\circ} \mathrm{C}, 1150{ }^{\circ} \mathrm{C}, 1300^{\circ} \mathrm{C}$ e $1400{ }^{\circ} \mathrm{C}$.

[Figure 5: SEM micrographs of composition F sintered at $1100^{\circ} \mathrm{C}$, $1150{ }^{\circ} \mathrm{C}, 1300^{\circ} \mathrm{C}$, and $1400^{\circ} \mathrm{C}$.]

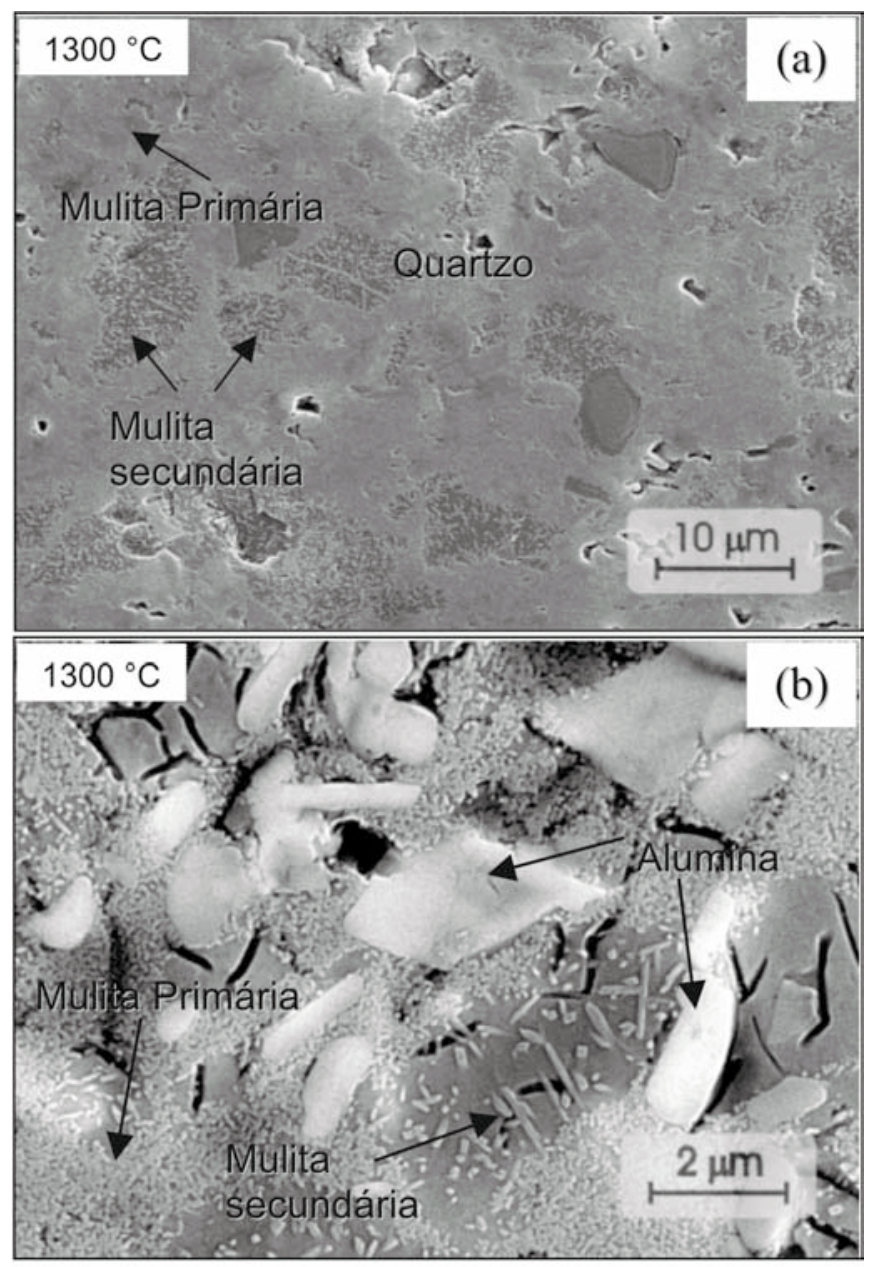

Figura 6: Micrografias obtidas por MEV da composição F sinterizada a $1300{ }^{\circ} \mathrm{C}$; (a) elétrons secundários; (b) elétrons retroespalhados. [Figure 6: SEM micrographs of composition F sintered at $1300^{\circ} \mathrm{C}$; (a) secondary electrons; (b) backscattered electrons.] a $1400^{\circ} \mathrm{C}$ o valor da densidade é praticamente constante. Para temperaturas acima de $1400{ }^{\circ} \mathrm{C}$ começa a ocorrer o aparecimento de poros formados pelo aprisionamento de gases caracterizando super queima. Estes poros aumentam de tamanho devido ao aumento de pressão do gás com a elevação da temperatura, provocando um inchaço da peça e redução da densidade.

A Fig. 4 mostra a variação dimensional com a temperatura e sua derivada primeira de uma amostra da composição F.

Foram determinados três intervalos de temperatura nos quais ocorrem retrações da amostra sendo:

-A retração ocorrida no primeiro intervalo de temperatura está relacionada com a transformação da caulinita em metacaulinita sendo a máxima taxa de retração a $551^{\circ} \mathrm{C}$.

- A segunda retração é devido à formação da fase espinélio a partir da metacaulinita e tem máxima taxa de retração a $965^{\circ} \mathrm{C}$.

- A terceira retração está associada à formação da fase líquida. $\mathrm{O}$ início da formação da fase líquida ocorreu ao redor de $1100^{\circ} \mathrm{C}$ e teve a máxima taxa de retração em $1178^{\circ} \mathrm{C}$. Esta máxima taxa de retração está associada ao processo de rearranjo das partículas devido à presença da fase líquida [3].

Foi detectada ainda uma mudança na taxa de retração entre $1200^{\circ} \mathrm{C}$ e $1250^{\circ} \mathrm{C}$ a qual é atribuída ao início do processo de dissolução e reprecipitação já detectado na medida de densidade, Fig. 3. A retração total desta composição foi de $18 \%$ para o programa de sinterização utilizado.

A análise da microestrutura de porcelanas deve ser feita, no mínimo, em baixo $(\sim 150 \mathrm{X})$, médio $(\sim 3.000 \mathrm{X})$ e alto $(\sim 10.000 \mathrm{X})$ aumento pois, em cada um desses aumentos é possível detectar defeitos ou características da amostra que são determinantes no valor da resistência mecânica. Por exemplo, em baixo aumento é detectada a presença de poros resultantes de coalescência ou de super queima, em médio aumento é observada a distribuição da fase líquida e somente em alto aumento é possível observar os grãos de mulita.

Na Fig. 5 são mostradas micrografias da composição $F$

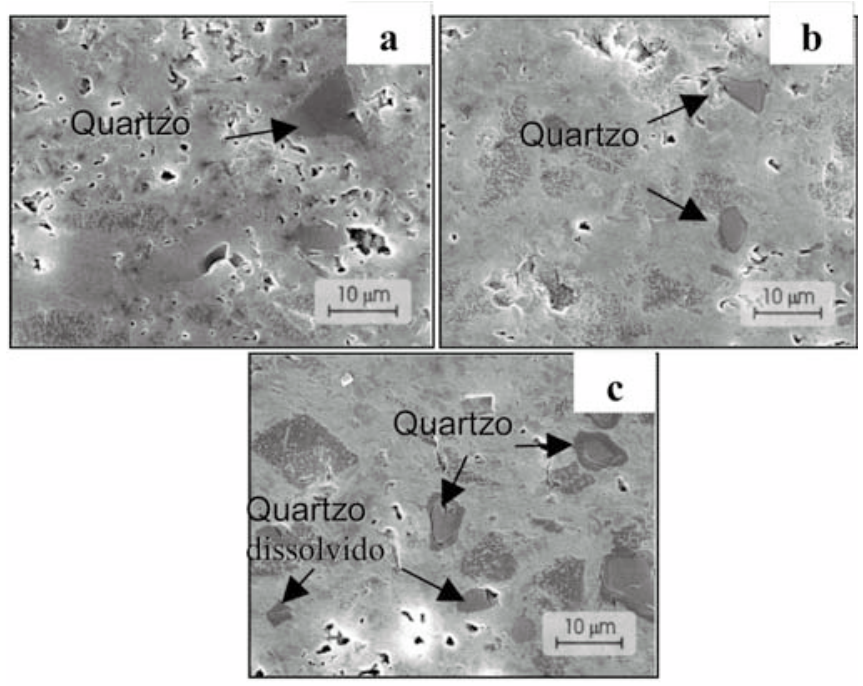

Figura 7: Evolução da dissolução de quartzo com a temperatura de sinterização: a) $1250{ }^{\circ} \mathrm{C}$; b) $1300{ }^{\circ} \mathrm{C}$; c) $1350{ }^{\circ} \mathrm{C}$.

[Figure 7: Evolution of quartzo dissolution at increasing sintering temperature: a) $1250^{\circ} \mathrm{C}$; b) $1300^{\circ} \mathrm{C}$; c) $1350{ }^{\circ} \mathrm{C}$.] 


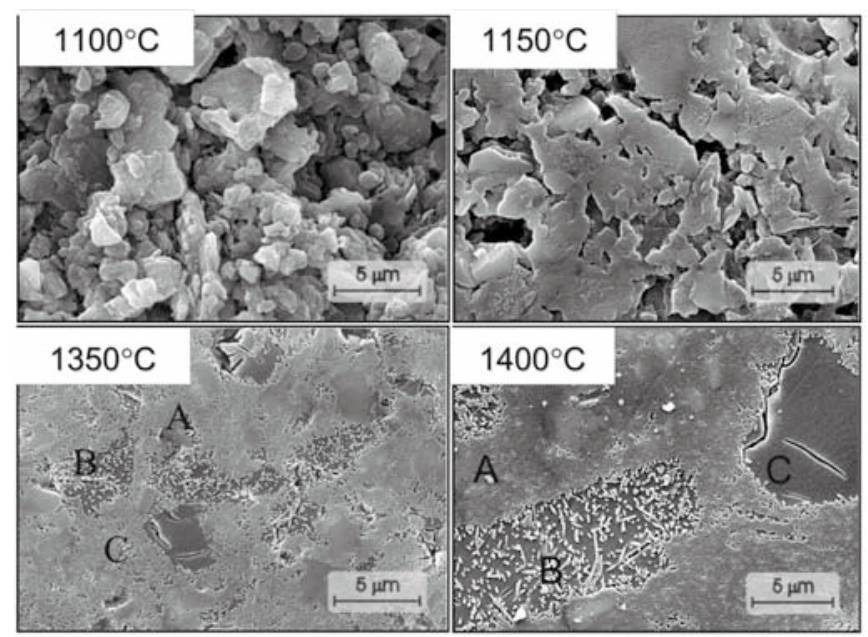

Figura 8: Micrografias obtidas por MEV da composição F sinterizada a: $1100{ }^{\circ} \mathrm{C}, 1150{ }^{\circ} \mathrm{C}, 1350{ }^{\circ} \mathrm{C}$ e $1400{ }^{\circ} \mathrm{C}$

[Figure 8: SEM micrographs of composition F sintered at $1100^{\circ} \mathrm{C}$, $1150^{\circ} \mathrm{C}, 1350^{\circ} \mathrm{C}$, and $1400^{\circ} \mathrm{C}$. $]$

obtidas com baixo aumento por microscopia eletrônica de varredura, MEV, de amostras sinterizadas em diferentes temperaturas. $\mathrm{Na}$ amostra sinterizada a $1100{ }^{\circ} \mathrm{C}$ a microestrutura é extremamente porosa e na amostra sinterizada a $1400{ }^{\circ} \mathrm{C}$ já é observado a ocorrência da super queima que é responsável pela diminuição da densidade nesta temperatura de sinterização como mostrado na Fig. 3.

Nas Figs. 6(a) e 6(b) são mostradas as micrografias, obtidas por MEV com médio e alto aumento, da composição $\mathrm{F}$ sinterizada a $1300^{\circ} \mathrm{C}$.

As seguintes fases podem ser observadas: mulita primária, mulita secundária, alumina, fase vítrea e quartzo. Importante enfatizar que essas partículas de quartzo foram introduzidas via matérias-primas. Os cristais de mulita primária aparecem na forma de um agregado de pequenos cristais envolvidos pela fase vítrea. A mulita secundária aparece como pequenos cristais com forma de agulhas, espalhados em uma região de fase vítrea. A identificação de cada fase foi feita com base no resultado da análise de EDS, na morfologia de cada fase e de acordo com a resposta obtida utilizando elétrons secundários ou retroespalhados. Por exemplo, a alumina pode ser observada como grãos mais claros na micrografia obtida com elétrons retroespalhados. O quartzo possui um contorno de fase vítrea isenta de mulita. Este contorno é fruto da dissolução parcial do quartzo na fase líquida modificando sua composição química nesta região.

A Fig. 7 mostra micrografias de amostras sinterizadas a $1250{ }^{\circ} \mathrm{C}, 1300{ }^{\circ} \mathrm{C}$ e $1350{ }^{\circ} \mathrm{C}$ onde pode ser observada com nitidez a contínua dissolução das partículas de quartzo, com conseqüente modificação na sua forma e surgimento do contorno ao seu redor como mencionado anteriormente. Outra característica importante a ser observada na micrografia $7 \mathrm{c}$ é a trinca em torno da partícula de quartzo devido sua redução de volume no resfriamento como conseqüência da transição de fase $\beta \rightarrow \alpha$. Este defeito é responsável pela baixa resistência mecânica das porcelanas de quartzo como abordado na parte I [1].

Na Fig. 8 é mostrada a evolução das fases na microestrutura com a temperatura de sinterização da composição F.

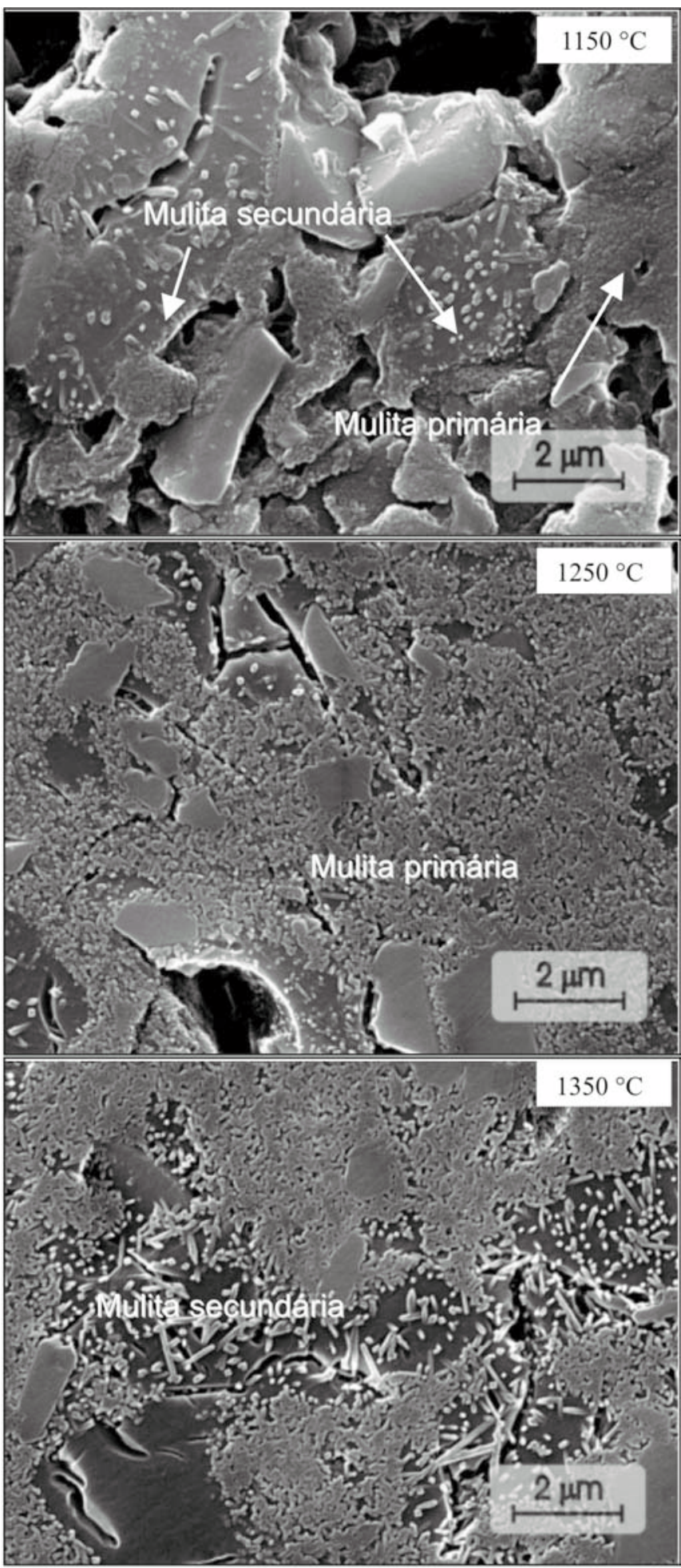

Figura 9: Micrografias obtidas por MEV da composição F sinterizada a $1150{ }^{\circ} \mathrm{C}, 1250{ }^{\circ} \mathrm{C}$ e $1350{ }^{\circ} \mathrm{C}$.

[Figure 9: SEM micrographs of composition F sintered at $1150^{\circ} \mathrm{C}$, $1250^{\circ} \mathrm{C}$, and $1350^{\circ} \mathrm{C}$.]

A $1100^{\circ} \mathrm{C}$ a microestrutura é formada por partículas unidas por fase vítrea localizada no contato entre elas. A quantidade de líquido presente nesta temperatura de sinterização ainda é pequena, não sendo suficiente para promover o rearranjo das partículas. Na temperatura de sinterização de $1150{ }^{\circ} \mathrm{C}$ a 


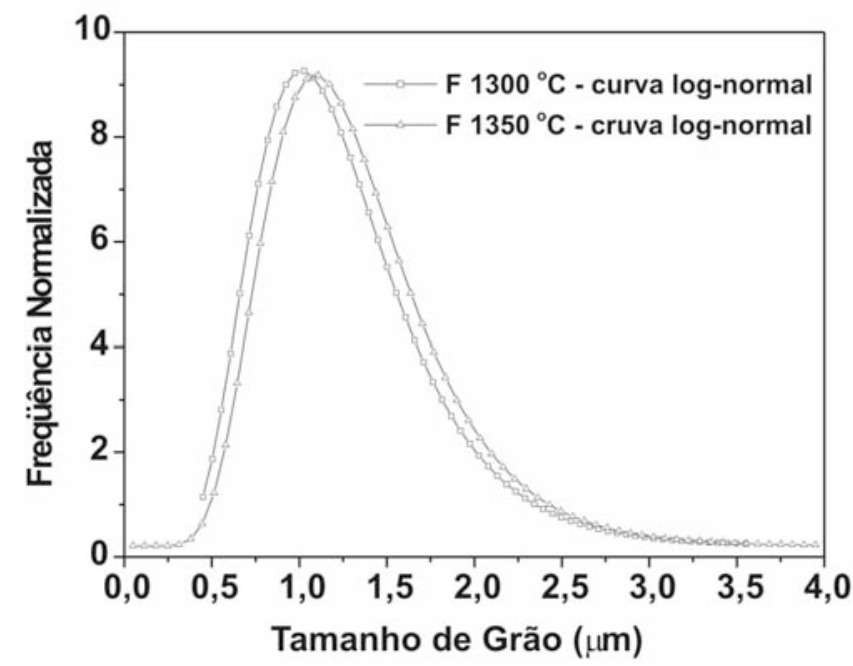

Figura 10: Distribuição do tamanho de grão de alumina nos corpos sinterizados da composição F.

[Figure 10: Grain size distribution of the alumina grain in the sintered body of the composition F.]

quantidade de líquido presente é suficiente para começar o processo de rearranjo das partículas eliminando parte da porosidade, entretanto ainda é grande o volume de poros interconectados. Nas amostras sinterizadas a $1350{ }^{\circ} \mathrm{C}$ e $1400{ }^{\circ} \mathrm{C}$, a mulita secundária aparece como cristais alongados imersos em algumas regiões de fase vítrea (região B) cercadas por mulita primária (região A). Nestas temperaturas de sinterização, aparecem também regiões de fase vítrea livres de mulita secundária (região C). Estas regiões foram formadas pela dissolução total da partícula de quartzo e mantém a forma original da partícula que se dissolveu.

Nas micrografias da Fig. 9, obtidas com alto aumento, é mostrado a evolução da mulita primária e secundária na faixa de temperatura de sinterização entre $1150{ }^{\circ} \mathrm{C}$ e $1350{ }^{\circ} \mathrm{C}$.

Na temperatura de $1150^{\circ} \mathrm{C}$ é possível observar que a mulita secundária foi formada na região de fase vítrea. Esta mulita cresce a partir da interface entre a fase vítrea e as regiões de mulita primária provenientes da caulinita em direção ao centro da fase vítrea [4]. Os cristais de mulita primária sofrem pequeno aumento de tamanho com a elevação da temperatura de sinterização.

Como abordado na parte I [1], a resistência mecânica da porcelana aluminosa é dependente do tamanho das partículas de alumina dispersa na microestrutura. Portanto, é importante determinar se ocorre dissolução das partículas de alumina na fase líquida durante a sinterização. A análise de micrografias obtidas por MEV permitiu traçar a distribuição de tamanhos das partículas de alumina dispersas na microestrutura.

A Fig. 10 mostra as distribuições obtidas para as amostras

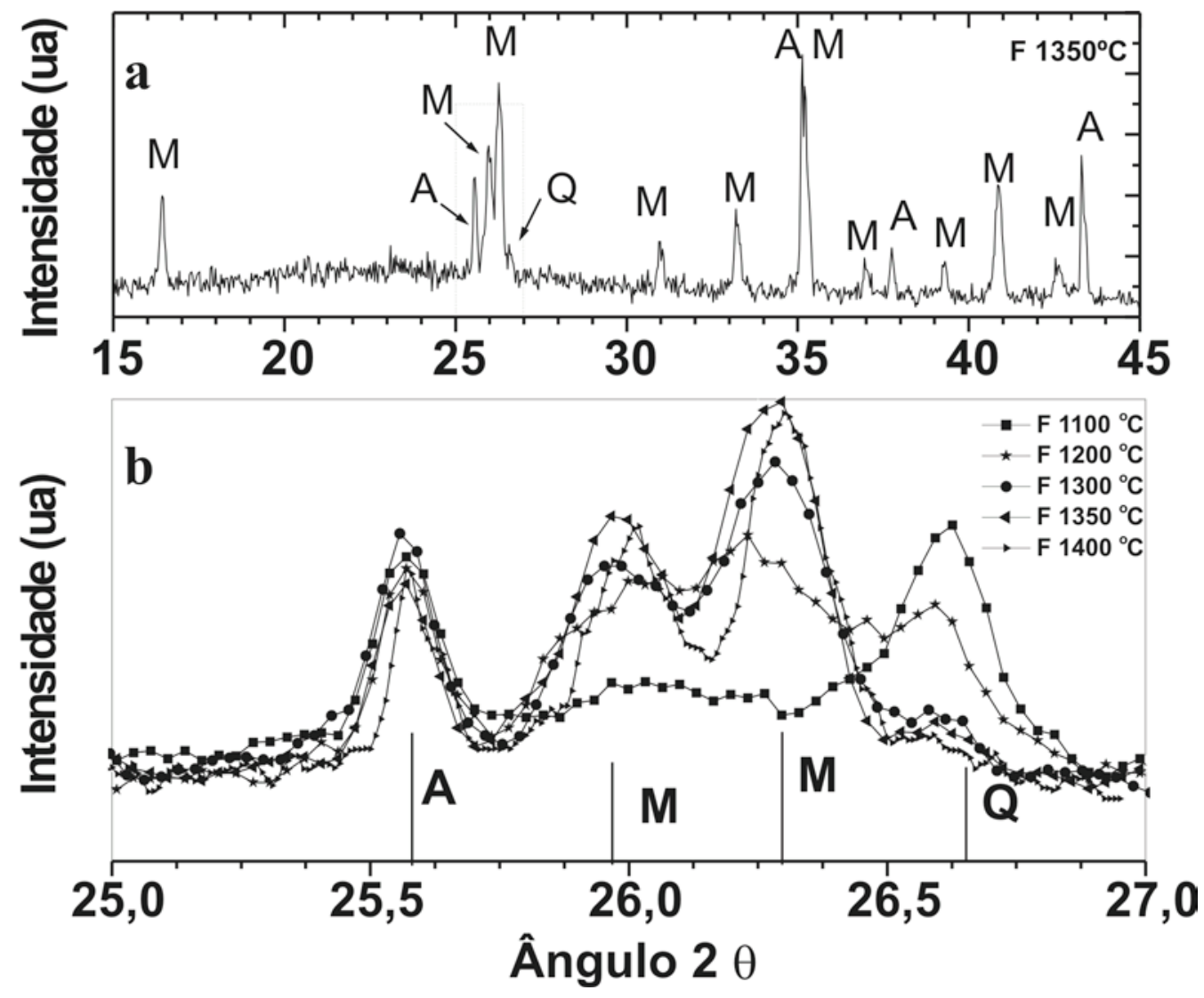

Figura 11: Difratograma de raios X da composição F sinterizada em várias temperaturas; varredura: $2 \% \mathrm{~min} ; \mathrm{M}=$ mulita, $\mathrm{Q}=$ quartzo e $\mathrm{A}=$ alumina [Figure 11: XRD patterns of composition F sintered at several temperatures; scanning: $2 \%$ min; $M=$ mullite, $Q=$ quartz, and $A=$ alumina.] 

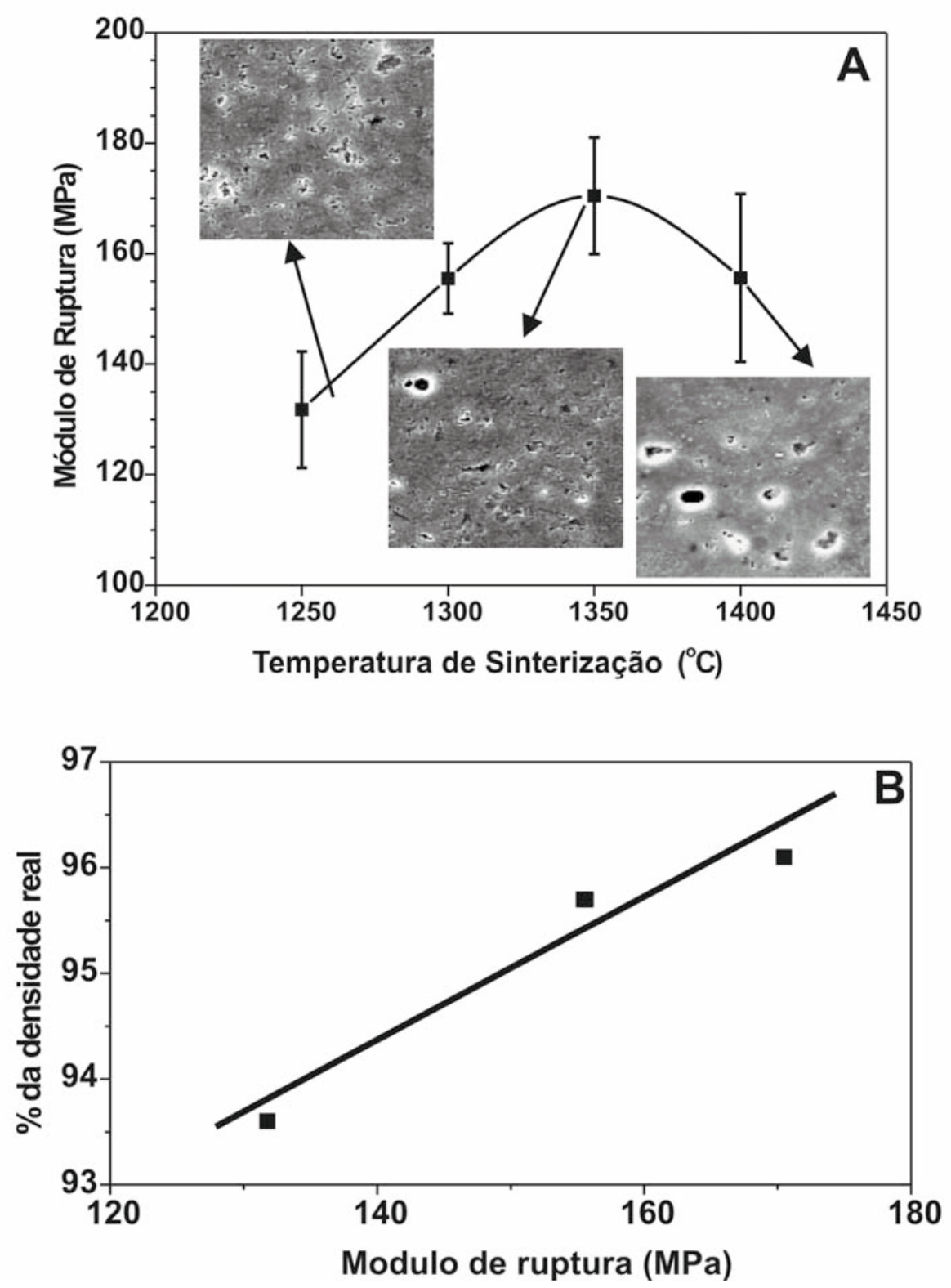

Figura 12: a) Módulo de ruptura da composição F versus temperatura de sinterização; b) Porcentagem da densidade real versus módulo de ruptura. [Figure 12: a) Bending strength of composition $F$ as a function of sintering temperature; b) Percentage of theoretical density as a function of bending strength.]

sinterizadas a $1300^{\circ} \mathrm{C}$ e $1350{ }^{\circ} \mathrm{C}$.

O tamanho médio aritmético das partículas para as duas temperaturas de sinterização foi de $(1,3 \pm 0,5) \mu \mathrm{m}$. A análise estatística através do teste-t de Student para estas duas distribuições log-normal, fornece uma probabilidade de $18 \%$ destas distribuições serem idênticas, o que é superior ao valor de 5\% que normalmente é aceito [5]. Portanto, não existe diferença significativa nas distribuições de tamanhos de grãos nesta faixa de temperatura. Considerando que o tamanho médio inicial das partículas de alumina era de $1,70 \mu \mathrm{m}$, Fig. 2, e que não ocorreu redução do tamanho das partículas quando a temperatura de sinterização foi aumentada de $1300{ }^{\circ} \mathrm{C}$ para $1350{ }^{\circ} \mathrm{C}$, pode ser suposto que não ocorreu dissolução das partículas durante a sinterização e sim redução do tamanho durante a etapa de mistura das matérias-primas.

Na Fig. 11a é mostrado o espectro completo de difração de raios X da composição F sinterizada a $1350{ }^{\circ} \mathrm{C}$ e na Fig. $11 \mathrm{~b}$ é mostrado parte do espectro, com $2 \theta$ entre $25^{\circ}$ e $27^{\circ}$, para várias temperaturas de sinterização.

Foram identificadas 3 fases: quartzo, alumina- $\alpha$ e mulita, as quais foram designadas por Q, A e M, respectivamente. A intensidade dos picos de quartzo diminui com o aumento da temperatura de sinterização, sendo que a maior redução foi observada entre $1200{ }^{\circ} \mathrm{C}$ e $1250{ }^{\circ} \mathrm{C}$. Picos característicos da mulita já aparecem a $1100{ }^{\circ} \mathrm{C}$ e aumentam sua intensidade com o aumento da temperatura de sinterização, confirmando o que foi observado por microscopia eletrônica de varredura, Fig. 9. A intensidade dos picos de alumina permanece 
praticamente inalterada em todas as temperaturas.

O tamanho dos cristalitos de mulita foram medidos a partir dos espectros de difração de raios X utilizando o método de Scherrer e foi determinado que com a elevação da temperatura de sinterização ocorreu o crescimento dos cristalitos, Tabela III, confirmando o que foi observado por microscopia eletrônica de varredura.

A Fig. 12a mostra valores do módulo de ruptura em função da temperatura de sinterização.

O máximo valor do módulo de ruptura para esta composição foi de $170 \mathrm{MPa}$ obtido nas amostras sinterizadas a $1350^{\circ} \mathrm{C}$. De acordo com o apresentado na parte I [1], o módulo de ruptura é dependente de: quantidade de mulita, porosidade, tamanho dos grãos de alumina, tamanho dos grãos de quartzo ou composição da fase vítrea. A quantidade de mulita aumenta continuamente com a temperatura de sinterização não sendo portanto responsável pela diminuição do módulo de ruptura acima de $1350{ }^{\circ} \mathrm{C}$. $\mathrm{O}$ tamanho médio dos grãos de alumina não varia entre $1300^{\circ} \mathrm{C}$ e $1350{ }^{\circ} \mathrm{C}$ como mostrado na Fig. 10, não podendo então estar influenciando no comportamento do módulo de ruptura com a temperatura de sinterização. O quartzo está quase totalmente dissolvido na temperatura de $1300^{\circ} \mathrm{C}$. Assim, os únicos fatores que poderiam estar influenciando o comportamento do módulo de ruptura seriam: a variação da composição da fase vítrea ou a variação da porosidade. A Fig. 12b mostra que a relação entre a porcentagem da densidade real e o módulo de ruptura é aproximadamente linear o que concorda com resultados publicados [6]. Portanto, a variação do módulo de ruptura da composição $\mathrm{F}$ com a temperatura de sinterização é determinada pela porosidade, isto é, até $1350^{\circ} \mathrm{C}$ ocorre redução da porosidade e aumento do módulo de ruptura e a partir desta temperatura inicia o surgimento de poros devido ao início da super queima provocando a redução do módulo de ruptura.

Composição G (18\% de feldspato, 18\% de caulim e 54\% alumina)

Na Fig. 13 são apresentados os valores da densidade da composição $\mathrm{G}$ em função da temperatura de sinterização. Para esta composição a maior densidade encontrada foi $2,91 \mathrm{~g} /$ $\mathrm{cm}^{3}$ para a temperatura de sinterização de $1400{ }^{\circ} \mathrm{C}$, diminuindo ligeiramente quando a temperatura é elevada para $1450{ }^{\circ} \mathrm{C}$. A curva mostra uma mudança de comportamento como na composição $\mathrm{F}$, entretanto esta mudança ocorre ao redor de $1350{ }^{\circ} \mathrm{C}$.

Na Fig. 14 são apresentadas as curvas de variação dimensional e sua derivada primeira. Estas curvas mostram a transformação da caulinita em metacaulinita com a máxima taxa de retração ocorrendo em $514{ }^{\circ} \mathrm{C}$ e a transformação de metacaulinita na fase espinélio com a máxima taxa de retração em $955^{\circ} \mathrm{C}$. O início da formação da fase líquida ocorre ao redor de $1050^{\circ} \mathrm{C}$ favorecendo o rearranjo das partículas e a máxima taxa de retração devido a este processo ocorre em $1166^{\circ} \mathrm{C}$. Outro pico na taxa de retração é observado a $1385{ }^{\circ} \mathrm{C}$ e está associado ao início do processo de dissolução-reprecipitação. A retração total desta composição foi de $14 \%$ para o programa de sinterização utilizado.

A Fig. 15 mostra as microestruturas obtidas por microscopia eletrônica de varredura para várias temperaturas de sinterização.
Tabela III - Tamanho de cristalito de mulita determinado pelo método de Scherrer.

[Table III - Size of mullite crystallite determined by Scherrer's method.]

\begin{tabular}{cc}
\hline Temperatura $\left({ }^{\circ} \mathrm{C}\right)$ & $\begin{array}{c}\text { Tamanho de cristalito } \\
\text { de mulita }(\mu \mathrm{m})\end{array}$ \\
\hline 1250 & $0,036 \pm 0,002$ \\
\hline 1300 & $0,042 \pm 0,002$ \\
\hline 1350 & $0,050 \pm 0,003$ \\
\hline 1400 & $0,060 \pm 0,002$ \\
\hline
\end{tabular}

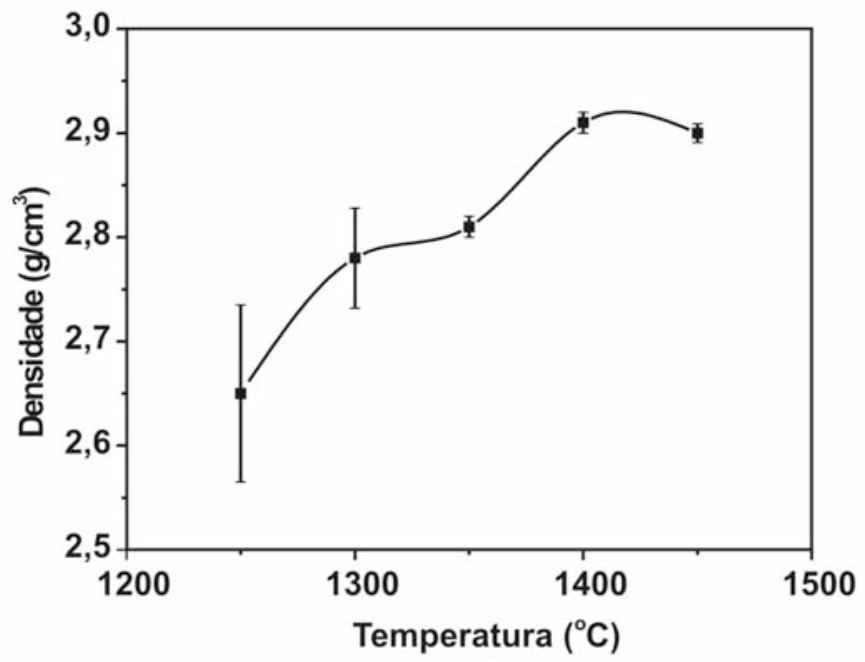

Figura 13: Densidade de amostras sinterizadas da composição G versus temperatura de sinterização..

[Figure 13: Density of sintered samples of composition $G$ as a function of sintering temperature.]

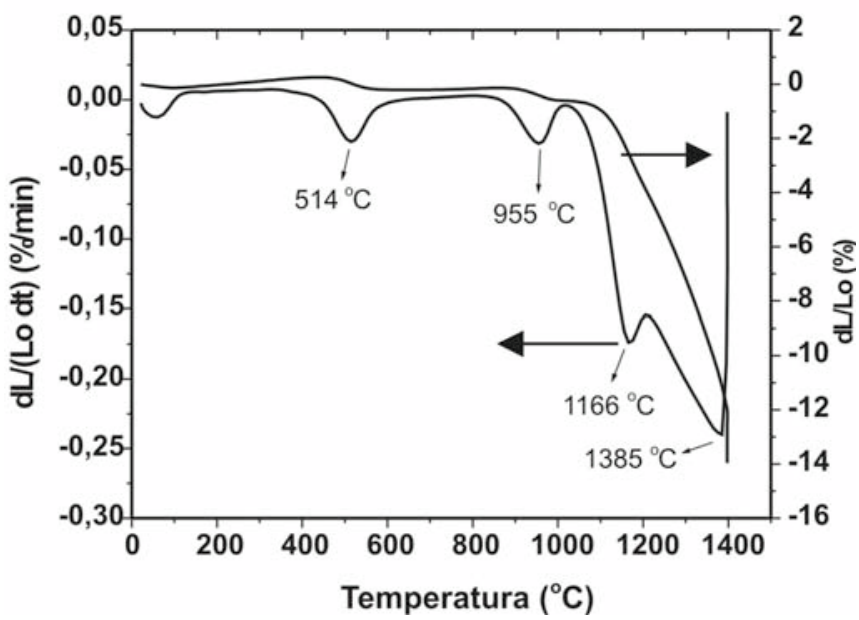

Figura 14: Variação dimensional e sua derivada primeira da composição G. Taxa de aquecimento: $5{ }^{\circ} \mathrm{C} / \mathrm{min}$.

[Figure 14: Dilatometric curves and the shrinkage rate as a function of temperature of composition $\mathrm{G}$; heating rate: $5{ }^{\circ} \mathrm{C} / \mathrm{min}$.] 


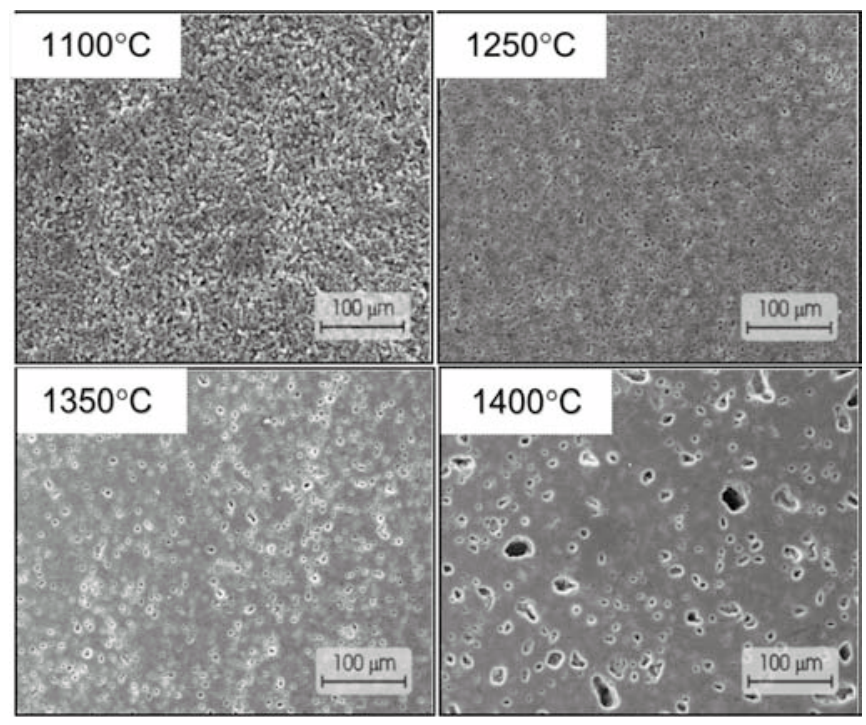

Figura 15: Micrografias obtidas por MEV da composição $\mathrm{G}$ sinterizada a: $1100{ }^{\circ} \mathrm{C}, 1250{ }^{\circ} \mathrm{C}, 1350{ }^{\circ} \mathrm{C}$ e $1400{ }^{\circ} \mathrm{C}$.

[Figure 15: SEM micrographs of composition $G$ sintered at $1100^{\circ} \mathrm{C}$, $1250{ }^{\circ} \mathrm{C}, 1350{ }^{\circ} \mathrm{C}$, and $1400^{\circ} \mathrm{C}$.]

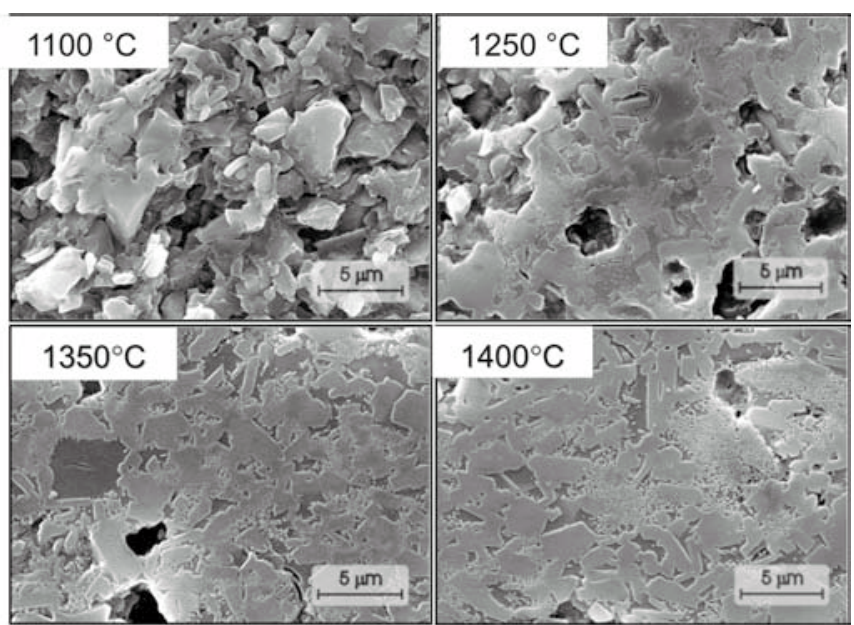

Figura 16: Micrografias obtidas por MEV da composição $\mathrm{G}$ sinterizada a: $1100{ }^{\circ} \mathrm{C}, 1250{ }^{\circ} \mathrm{C}, 1350{ }^{\circ} \mathrm{C}$ e $1400{ }^{\circ} \mathrm{C}$.

[Figure 16: SEM micrographs of composition $\mathrm{G}$ sintered at $1100^{\circ} \mathrm{C}$, $1250^{\circ} \mathrm{C}, \quad 1350^{\circ} \mathrm{C}$, and $1400^{\circ} \mathrm{C}$.]

A $1100{ }^{\circ} \mathrm{C}$ a microestrutura ainda é porosa pois está no início da formação da fase líquida. A partir de $1250{ }^{\circ} \mathrm{C}$ ocorre aumento no tamanho dos poros. Este aumento é atribuído à coalescência pois a densidade aumenta até $1400^{\circ} \mathrm{C}$, Fig. 13 .

A análise da microestrutura com maior aumento, Fig. 16, revela que a $1100{ }^{\circ} \mathrm{C}$ a quantidade de fase líquida é insuficiente para provocar o rearranjo das partículas e a microestrutura apresenta alta porosidade com poros interconectados. Com o aumento da temperatura de sinterização para $1250{ }^{\circ} \mathrm{C}$, a quantidade de fase líquida aumenta eliminando parte da porosidade, mas ainda é insuficiente para preencher totalmente os espaços vazios, e a microestrutura ainda é porosa. Acima de $1350^{\circ} \mathrm{C}$ os grãos de alumina já estão unidos formando um esqueleto.

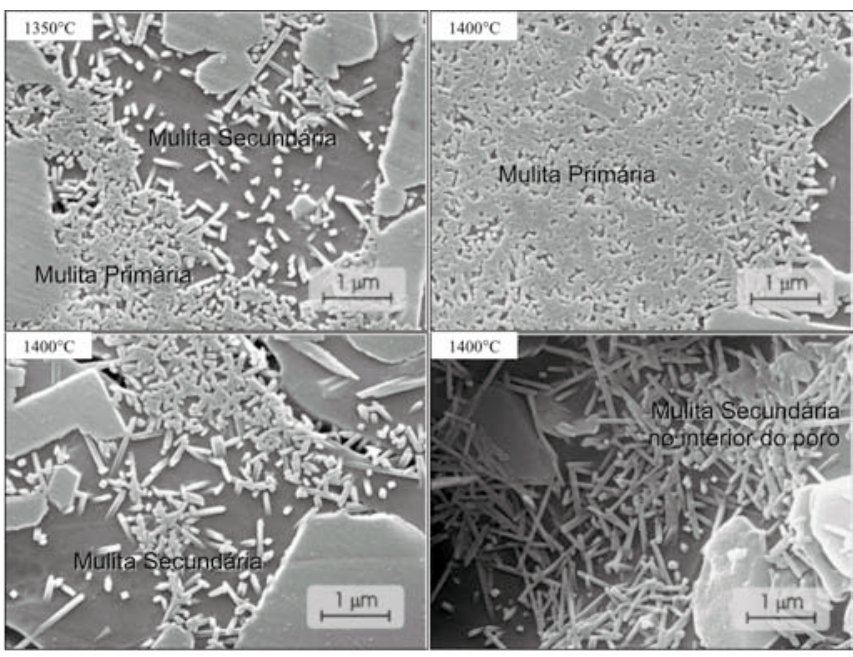

Figura 17: Micrografias obtidas por MEV da composição G sinterizada a: $1350{ }^{\circ} \mathrm{C}$ e $1400{ }^{\circ} \mathrm{C}$.

[Figure 17: SEM micrographs of composition $G$ sintered at $1350^{\circ} \mathrm{C}$ and $1400^{\circ} \mathrm{C}$.]
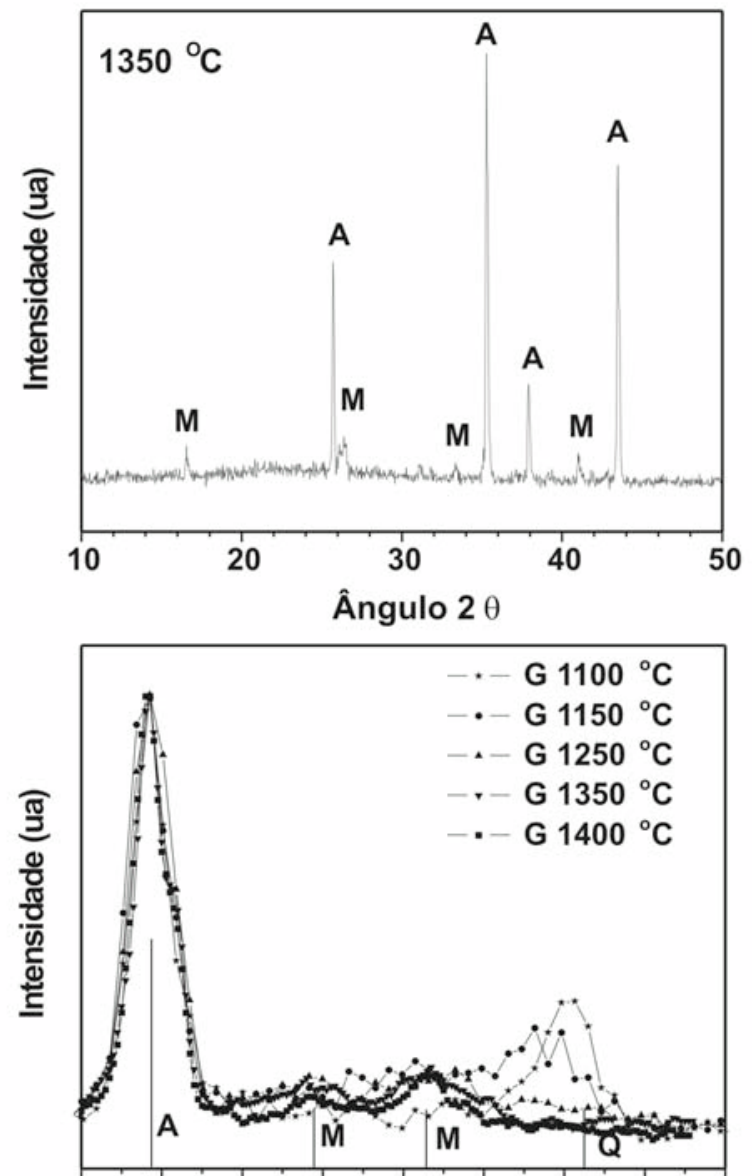

$\begin{array}{lllllllll}25,4 & 25,6 & 25,8 & 26,0 & 26,2 & 26,4 & 26,6 & 26,8 & 27,0\end{array}$

Ângulo $2 \theta$

Figura 18: Difratogramas de raios $\mathrm{X}$ da composição $\mathrm{G}$ sinterizada a $1350{ }^{\circ} \mathrm{C}$; varredura: $2 \% \mathrm{~min} ; \mathrm{M}=$ mulita; $\mathrm{A}=$ alumina.

[Figure 18: XRD patterns of composition $G$ sintered at several temperatures; scanning: $2 \% \mathrm{~min} ; M=$ mullite, $Q=$ quartz, and $A=$ alumina. $]$ 


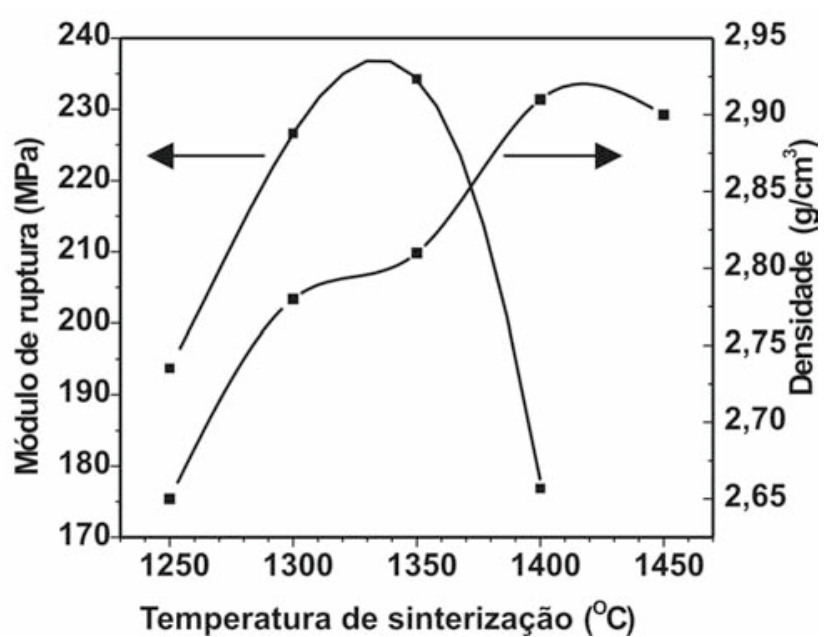

Figura 19: Módulo de ruptura e densidade de amostras da composição $\mathrm{G}$ versus temperatura de sinterização.

[Figure 19: Bending strength and density of samples of composition $G$ as a function of sintering temperature.]

Uma observação mais detalhada das amostras sinterizadas a $1350{ }^{\circ} \mathrm{C}$ e $1400^{\circ} \mathrm{C}$, Fig. 17 , mostra que a mulita secundária está presente em pequena quantidade e em regiões de fase vítrea cercada pela mulita primária e no interior de alguns poros. A mulita primária apresenta cristais maiores que os encontrados para a composição F sinterizados na mesma temperatura sendo $0,050 \mu \mathrm{m}$ na composição $\mathrm{Fe} \mathrm{e} 0,064 \mu \mathrm{m}$ na composição G quando sinterizadas a $1350{ }^{\circ} \mathrm{C}$.

A análise do tamanho das partículas de alumina dispersas na microestrutura forneceu resultado semelhante ao obtido para a composição $\mathrm{F}$, isto é, foi detectado pequena redução no tamanho comparado com o inicial sendo o tamanho médio de $1,1 \pm 0,5 \mu \mathrm{m}$ para a amostra sinterizada a $1200{ }^{\circ} \mathrm{C}$.

Os difratogramas de raios $\mathrm{X}$ da composição G, Fig. 18, mostram a presença das seguintes fases cristalinas: mulita, alumina- $\alpha$ e uma pequena quantidade de quartzo. Os picos de difração característicos do quartzo praticamente desaparecem para temperatura de sinterização superior a $1250{ }^{\circ} \mathrm{C}$ enquanto que os da mulita apresentam um pequeno aumento quando a temperatura de sinterização varia de $1150{ }^{\circ} \mathrm{C}$ até $1400^{\circ} \mathrm{C}$. Já a intensidade dos picos característicos da alumina- $\alpha$ mantém a intensidade praticamente constante para temperaturas de sinterização de $1100{ }^{\circ} \mathrm{C}$ até $1400^{\circ} \mathrm{C}$.

O módulo de ruptura apresentou máximo valor para amostras sinterizadas a $1350{ }^{\circ} \mathrm{C}$ enquanto que o máximo valor de densidade ocorre a $1400{ }^{\circ} \mathrm{C}$, Fig. 19. Este comportamento é devido ao coalescimento dos poros como mostrado na Fig. 15.

Composição H (54\% de feldspato, 18\% de caulim e 18\% alumina)

A composição $H$ apresenta uma grande variação da densidade com a temperatura de sinterização devido ao elevado volume de fase líquida presente durante a sinterização. A maior densidade foi de $2,60 \mathrm{~g} / \mathrm{cm}^{3}$ obtida para amostras sinterizadas a $1150{ }^{\circ} \mathrm{C}$, Fig. 20 .

A curva de variação dimensional, Fig. 21, mostra uma

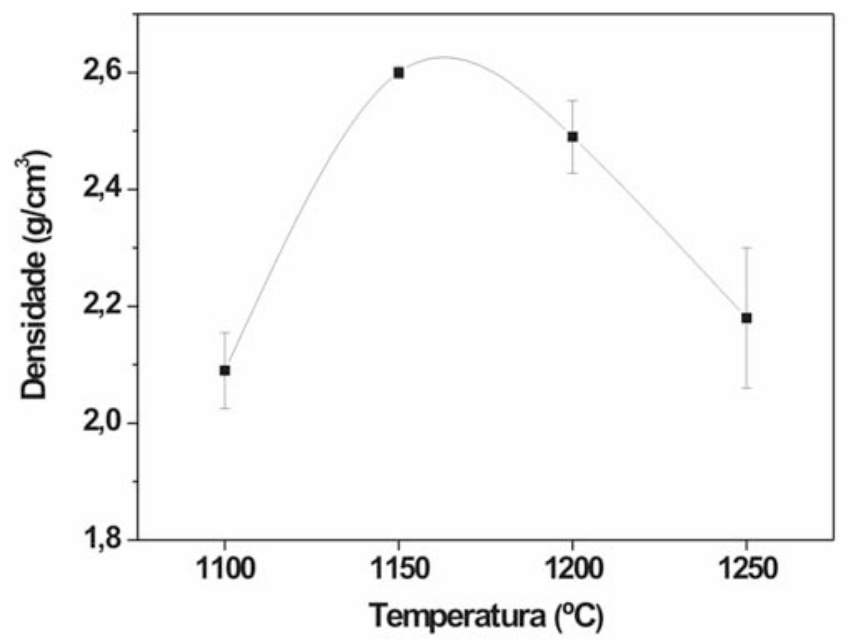

Figura 20: Densidade de amostras sinterizadas da composição H vesus temperatura de sinterização.

[Figure 20: Density of sintered samples of composition $H$ as a function of sintering temperature.]

retração de $13 \%$ para esta composição. A derivada primeira da retração mostra os picos característicos de formação da metacaulinita, formação da fase espinélio e de formação da fase líquida aparecendo nas temperaturas de 527, 966 e $1145{ }^{\circ} \mathrm{C}$ respectivamente. Nesta composição aparece apenas um valor de mínimo na taxa de retração durante a formação da fase líquida, não sendo observado o efeito gerado pela reação de dissolução e reprecipitação. Como existe uma elevada quantidade de fase líquida durante a sinterização o processo de rearranjo é suficiente para promover máxima densificação, não sendo detectado o processo de dissolução-reprecipitação. Este resultado é confirmado pela curva de densificação, Fig. 20 , que não apresenta variação de comportamento, como os encontrados para as composições $\mathrm{F}$ e $\mathrm{G}$.

A Fig. 22 mostra uma seqüência de micrografias obtidas em amostras sinterizadas entre $1100^{\circ} \mathrm{C}$ e $1250^{\circ} \mathrm{C}$. Observa-se que

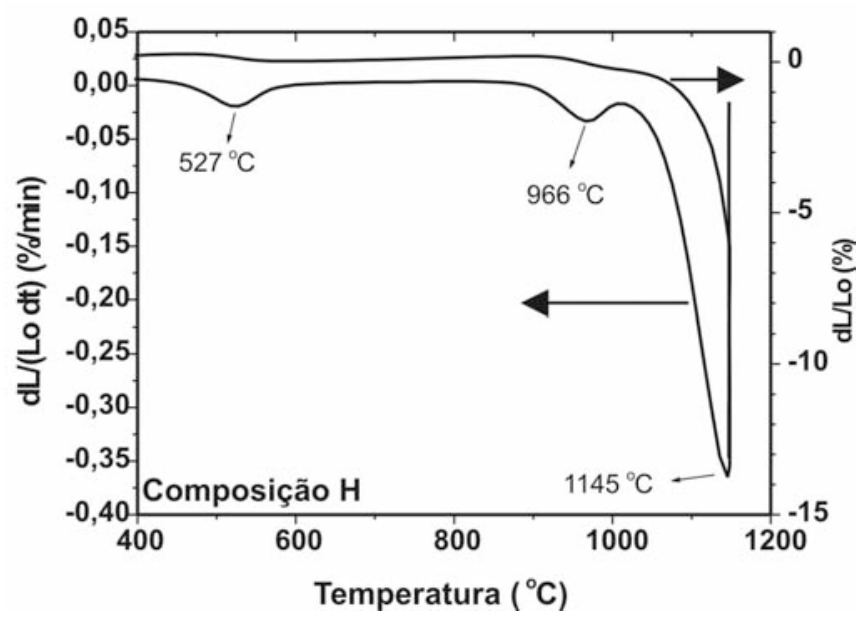

Figura 21: Variação dimensional e sua derivada primeira da composição H. Taxa de aquecimento: $5^{\circ} \mathrm{C} / \mathrm{min}$.

[Figure 21: Dilatometric curves and the shrinkage rate vs. temperature of composition $\mathrm{H}$; heating rate: $5^{\circ} \mathrm{C} / \mathrm{min}$.] 


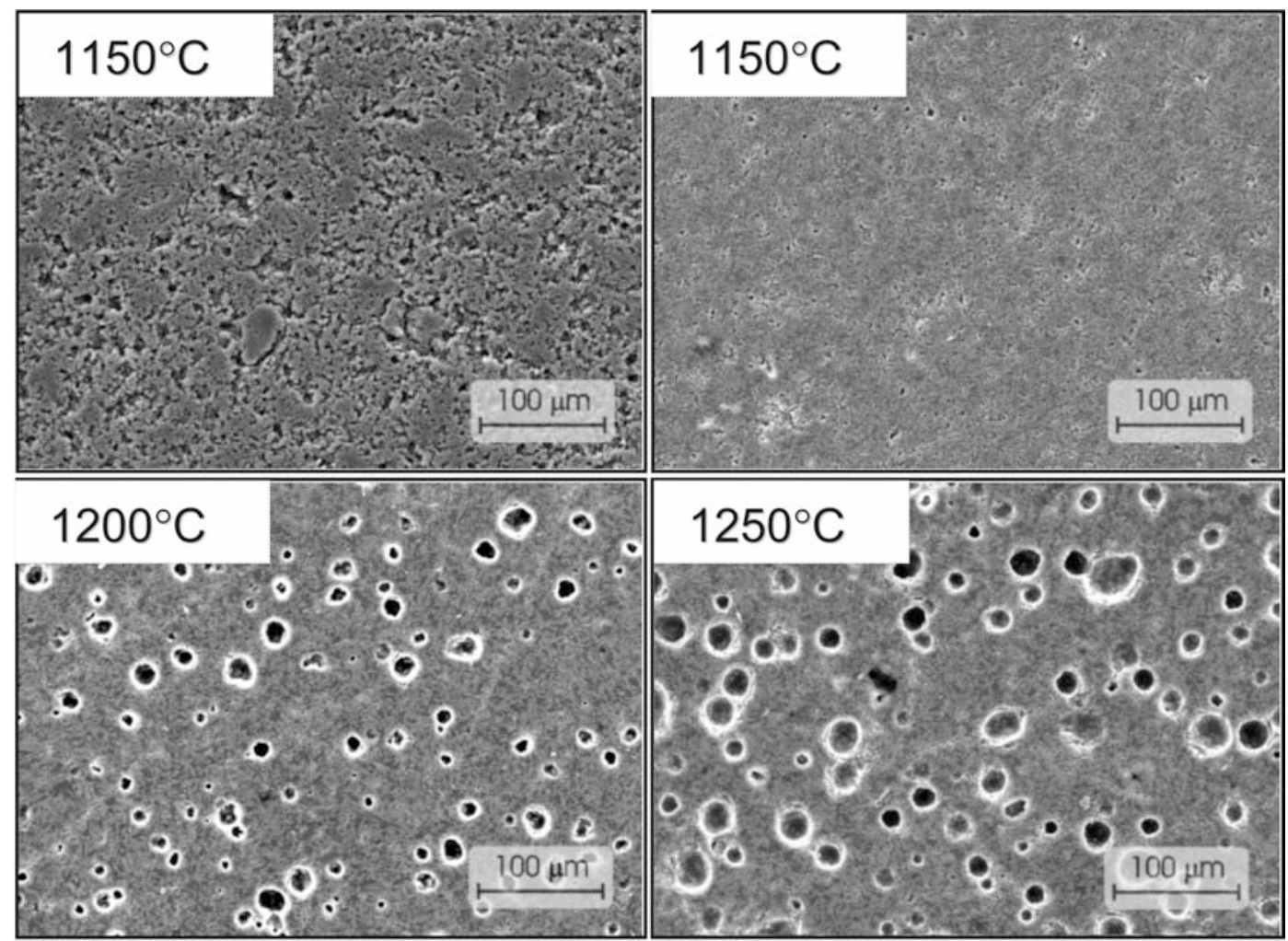

Figura 22: Micrografias obtidas por MEV da composição H sinterizada a: $1100^{\circ} \mathrm{C}, 1150{ }^{\circ} \mathrm{C}, 1200{ }^{\circ} \mathrm{C}$ e $1250{ }^{\circ} \mathrm{C}$. [Figure 22: SEM micrographs of composition H sintered at $1100^{\circ} \mathrm{C}, 1150{ }^{\circ} \mathrm{C}, 1200{ }^{\circ} \mathrm{C}$, and $1250{ }^{\circ} \mathrm{C}$.]

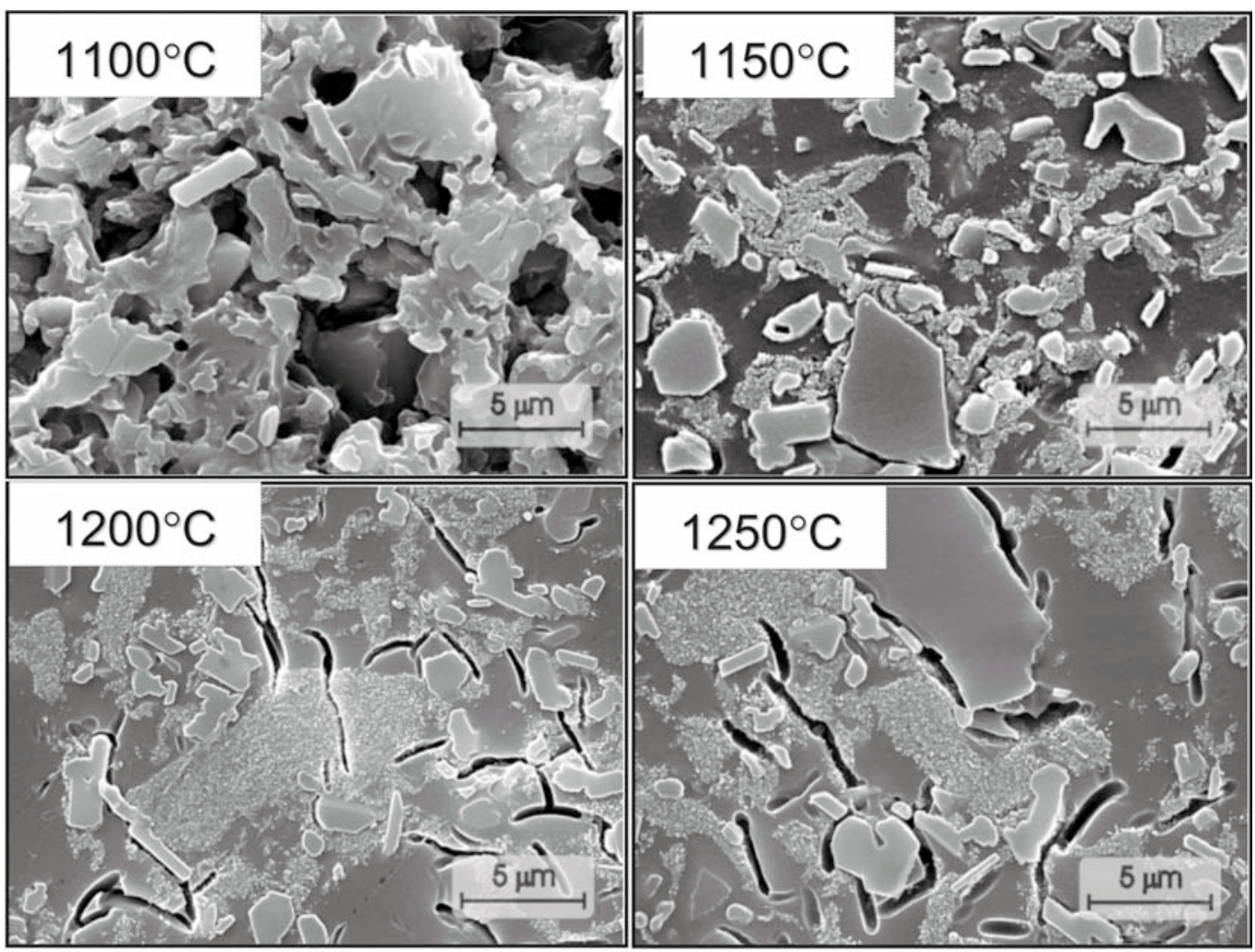

Figura 23: Micrografias obtidas por MEV da composição H sinterizada a: $1100{ }^{\circ} \mathrm{C}, 1150{ }^{\circ} \mathrm{C}, 1200^{\circ} \mathrm{C}$ e $1250{ }^{\circ} \mathrm{C}$. [Figure 23: Micrographs obtained by SEM of composition H sintered at $1100^{\circ} \mathrm{C}, 1150^{\circ} \mathrm{C}, 1200^{\circ} \mathrm{C}$, and $1250^{\circ} \mathrm{C}$.] 

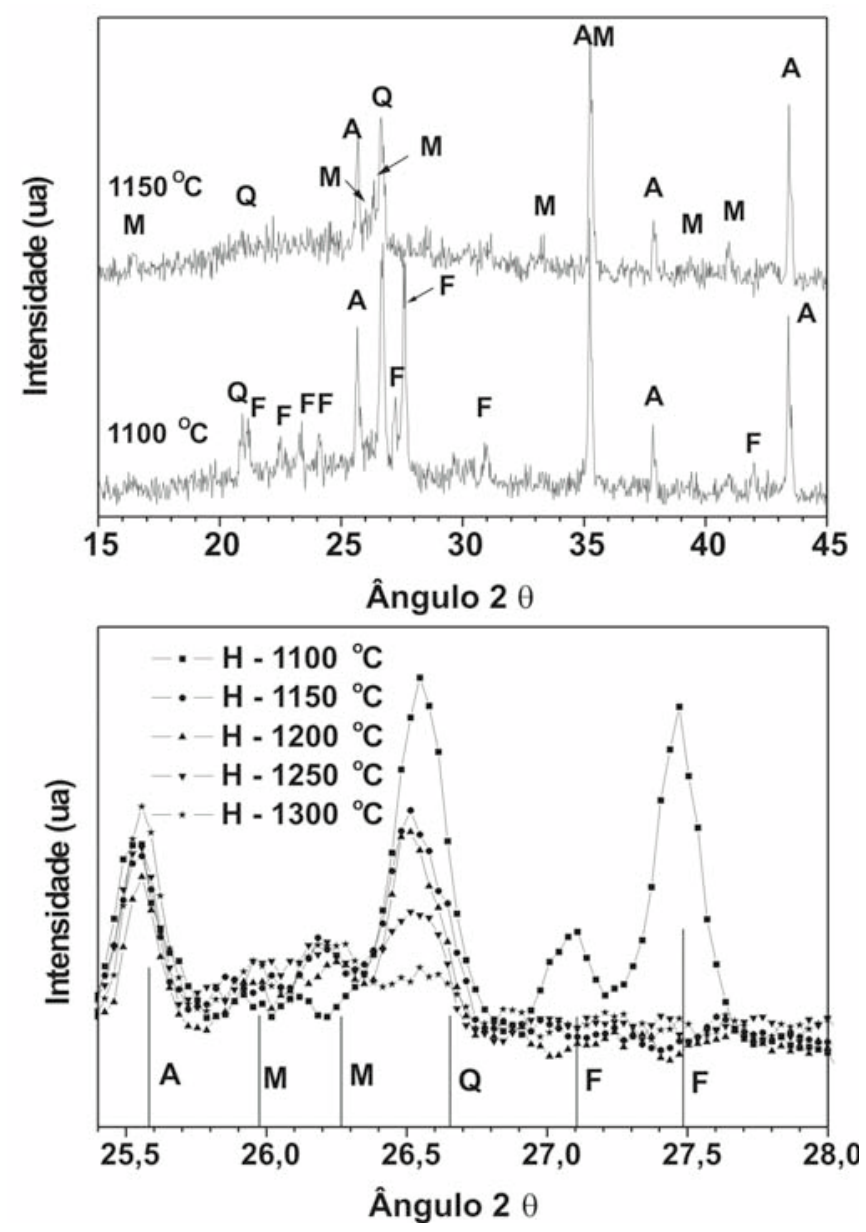

Figura 24: Difratogramas de raios $\mathrm{X}$ da composição $\mathrm{H}$; $\mathrm{M}=$ Mulita, $\mathrm{Q}=$ Quartzo, $\mathrm{A}=$ Alumina e $\mathrm{F}=$ Feldspato.

[Figure 24: XRD patterns of composition $H$; $M=$ mullite, $Q=$ quartz, $A=$ alumina, and $F=$ feldspar. $]$

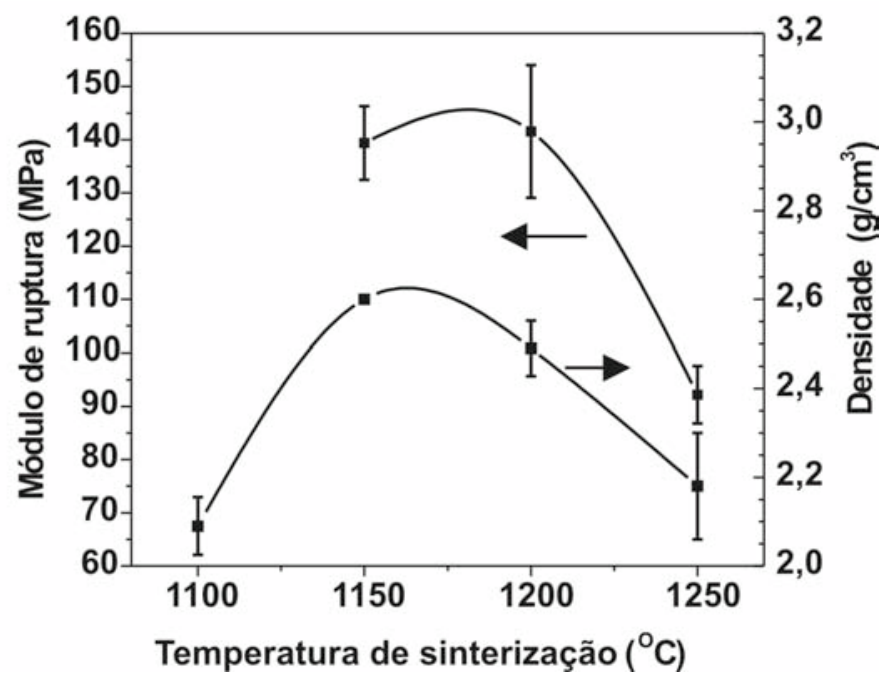

Figura 25: Densidade e módulo de ruptura de amostras sinterizadas da composição $\mathrm{H}$ versus temperatura de sinterização.

[Figure 25: Density and bending strength of sintered samples of composition $H$ as a function of sintering temperature.] variação de $50^{\circ} \mathrm{C}$ na temperatura de sinterização promove brusca modificação da microestrutura sendo que $1100^{\circ} \mathrm{C}$ ainda não é suficiente para eliminar toda a porosidade e $1200^{\circ} \mathrm{C}$ é suficiente para promover acentuada super queima. Neste caso o aumento dos poros com aumento da temperatura é atribuído à super queima pois foi observado concomitante redução da densidade, Fig. 20 diferentemente do que ocorreu na composição G.

Uma análise da microestrutura com maior aumento mostra que a $1100{ }^{\circ} \mathrm{C}$ a quantidade de fase líquida preenche parte dos espaços vazios, Fig. 23 . A $1150^{\circ} \mathrm{C}$ a fase líquida ocupa todos os espaços entre as fases cristalinas. Fissuras alongadas são observadas nas amostras sinterizadas a $1200{ }^{\circ} \mathrm{C}$ e $1250{ }^{\circ} \mathrm{C}$. Estas fissuras foram causadas pela presença de microtrincas, que ao serem atacadas pelo HF aumentam de tamanho. A mulita secundária não foi detectada em nenhuma amostra desta composição.

A análise da distribuição de tamanho das partículas de alumina nas amostras sinterizadas a $1200^{\circ} \mathrm{C}$ foi de $1,2 \pm 0,5 \mu \mathrm{m}$ seguindo o comportamento observado nas composições $\mathrm{F}$ e $\mathrm{G}$.

A análise de difração de raios $\mathrm{X}$ em amostras sinterizadas da composição $\mathrm{H}$ detectou grande quantidade de feldspato na forma de microcline a $1100^{\circ} \mathrm{C}$, sendo praticamente eliminado a $1150{ }^{\circ} \mathrm{C}$, Fig. 24. A quantidade de quartzo diminui acentuadamente entre $1200{ }^{\circ} \mathrm{C}$ e $1250{ }^{\circ} \mathrm{C}$, sendo quase totalmente dissolvido a $1300{ }^{\circ} \mathrm{C}$. Foi detectada pequena quantidade de mulita que sofreu crescimento com o aumento da temperatura de sinterização.

O módulo de ruptura de amostras da composição H, Fig. 25, mostra que o máximo valor foi obtido em amostras sinterizadas a $1200{ }^{\circ} \mathrm{C}$, diminuindo abruptamente nas amostras sinterizadas a $1250^{\circ} \mathrm{C}$. Esta diminuição é atribuída ao aumento do tamanho médio dos poros como também ao aparecimento de microtrincas observadas na microscopia eletrônica de varredura.

Comparação das composições estudadas: comparando a porcentagem da densidade real atingida por cada composição, Fig. 26, é observado que as composições $\mathrm{F}$ e $\mathrm{H}$ atingem

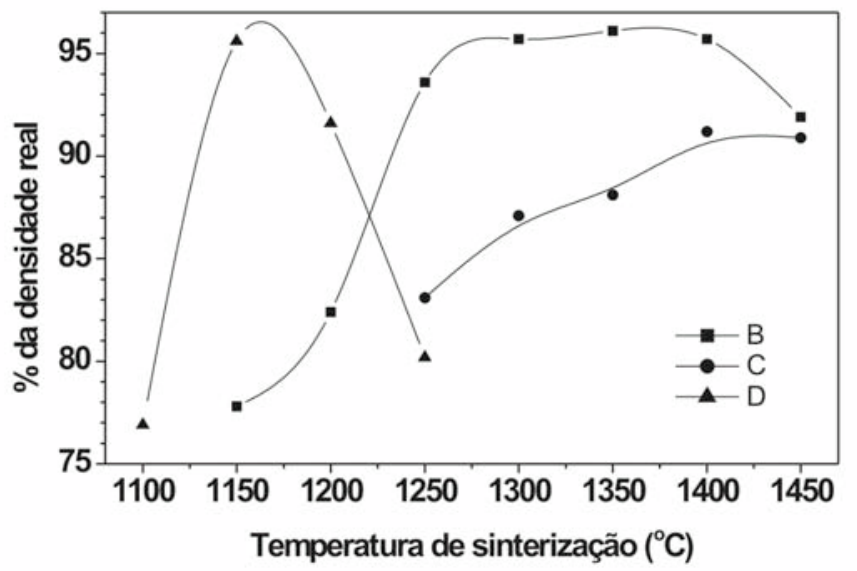

Figura 26: Porcentagem da densidade real de amostras sinterizadas das composições $\mathrm{F}, \mathrm{G}$ e $\mathrm{H}$, versus temperatura de sinterização. [Figure 26: Percentage of theoretical density of sintered samples of the compositions $F, G$, and $H$ as a function of sintering temperature.] 


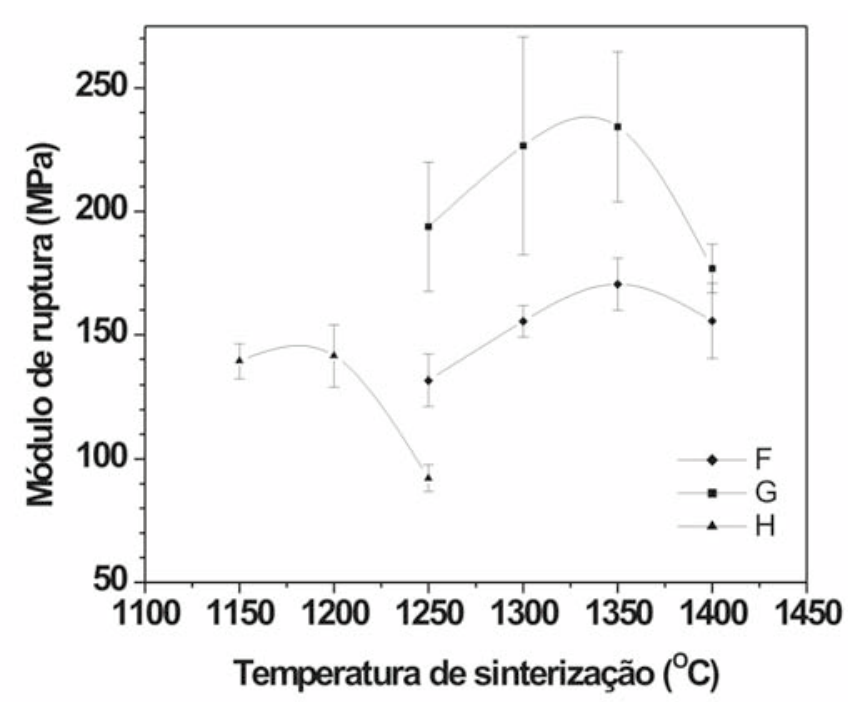

Figura 27: Módulo de ruptura de amostras sinterizadas das composições F, G e H versus temperatura de sinterização.

[Figure 27: Bending strength and density of sintered samples of compositions $F, G$, and $H$ as a function of sintering temperature.]

densidades de até $96 \%$ da densidade real enquanto que a composição $\mathrm{G}$ atinge, no máximo, $91 \%$ da densidade real. A densificação da composição $\mathrm{G}$ é dificultada pois, devido a grande quantidade de alumina os grãos se tocam limitando o processo de rearranjo. Contudo, esta composição apresenta o maior módulo de ruptura entre as três composições, Fig. 27.

Uma das maiores diferenças entre as três composições é a quantidade de mulita secundária. Não existe um consenso sobre a origem deste tipo de mulita como abordado na parte I [1]. Duas possibilidades são consideradas: nucleação e crescimento na fase líquida feldspáltica ou crescimento na fase líquida feldspáltica a partir de uma semente de mulita primária. Os resultados obtidos neste trabalho mostram que a composição que apresentou maior quantidade de cristais de mulita secundária foi a composição $\mathrm{F}$ que contém maior quantidade de caulim e, por conseqüência maior quantidade de cristais de mulita primária. Nas amostras de composição G, rica em alumina, e H, rica em feldspato, pequena quantidade de cristais de mulita secundária foi encontrada. Porém, a maior quantidade de cristais de mulita secundária na composição F pode não estar associada à apenas a maior quantidade de mulita primária mas também à composição da fase líquida. A microanálise quantitativa em microscópio eletrônico de transmissão da fase vítrea presente em amostras das composições $\mathrm{F}$ e $\mathrm{G}$ revelou que a relação $\mathrm{Si} / \mathrm{Al}$ para a composição $F$ é 4,85 enquanto que para a composição $G$ é 2,63. Portanto, a fase vítrea da composição $\mathrm{G}$ é mais rica em $\mathrm{Al}$ que a fase vítrea da composição $\mathrm{F}$.

\section{CONCLUSÃO}

Composições de porcelanas aluminosas nas quais o teor de alumina favorece a percolação apresentam maior dificuldade para densificação do que as composições ricas em caulim ou feldspato pois o processo de rearranjo das partículas é inibido pela formação do esqueleto de partículas de alumina e o processo de dissolução-reprecitação também é inibido pois as partículas de alumina não são solúveis na fase líquida.

O módulo de ruptura aumenta com a quantidade de fase cristalina presente na microestrutura sendo que as partículas de alumina são mais efetivas do que os cristais de mulita.

O módulo de ruptura apresenta um máximo com a temperatura de sinterização que é determinado pelo aparecimento de grandes poros em conseqüência de super queima ou da coalescência.

\section{AGRADECIMENTOS}

À CAPES pela bolsa PICDT de um dos autores (ALC).

\section{REFERÊNCIAS}

[1] A. L. Chinelatto, D. P. F. de Souza, Cerâmica 50, 313 (2004) 62-68.

[2] A. L. Chinelatto, "Efeito de Terras Raras no desenvolvimento da Microestrutura e nas Propriedades de Porcelanas Aluminosas" Tese (Doutorado em Ciência e Engenharia de Materiais), Programa de Pós-Graduação em Ciência e Engenharia de Materiais, Universidade Federal de S. Carlos, S. Carlos (2002) 147f.

[3] R. M. German, "Sintering theory and pratice", John Wiley\&Sons, New York (1996) p. 225.

[4] Y. Iqbl, W. E, Lee, J. Am. Ceram. Soc. 83, 12 (2000) 3121-3127.

[5] A. T Ring, "Fundamentals of ceramic powder processing and synthesis", Academic Press, San Diego (1996).

[6] N. Sugiyama, R. Harada, H. Ishida, J. Ceram. Soc. Jpn. Int. Editon 105, 2 (1997) 134-139.

(Rec. 29/09/03, Ac. 05/12/03) 